\title{
Effect of Nuclear radiation on polyvinyl chloride
}

\author{
H. A. Hussain* \\ hkhursan@yahoo.com
}

A. H. M. Al-Hashimi***

A. H. M. Al-Hashimi***

\begin{abstract}
*University of Basra - College of Science - Dept. of Physics.
***University of Basra - College of Medicine.

${ }^{* * *}$ University of Thi-Qar - College of Medicine - Dept. of Medical Physics.
\end{abstract}

\section{Abstract}

Charge particle effect have been work out on Polyvinyl chloride ( PVC ) and Nitrate cellulose (CN-85), this effect have been find out and compared together ( PVC and CN-85), by using optical density technique, this work for this polyvinyl chloride, have been done for the first time .

Polyvinyl chloride used in this work, shows more response and more linearity than $\mathrm{CN}-85$, in respond to alpha particle in dose range between $6 \mathrm{mGy}$ to $19 \mathrm{mGy}$.

$$
\text { * * تسين علي حسين الخرسان }
$$

الخحلاصة

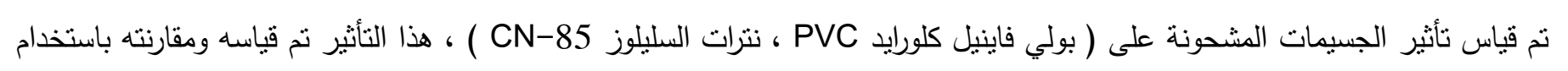

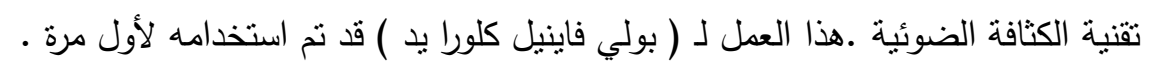
بولي فاينيل كلورايد المستخدم في هذا العمل ، اظهر أكثر استجابة خطيا من نترات السليلوز

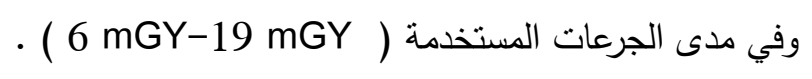




\section{1- Introduction}

Polymeric plastic materials are being increasingly used in a wide variety of application where they are routinely exposed to different kinds of nuclear radiations, these Solid State Plastic Nuclear Detectors (SSPND) have found a large field of applications in various domains of science, such as alpha particles measurements ${ }^{[1]}$ neutron flux measurement [2] nuclear physics [3], geochemistry ${ }^{[4-6]}$ or geochronology ${ }^{[7-10]}$.

Solid detectors present many advantages, such as a significant low cost as well as simplicity in exploration, ability to use in various geometries and sizes, an integrating nature, which allows events to accumulate over a long interval of time as well as a differential sensitivity to charged particles such as alpha particles, protons, or fission fragments, making them very popular among scholars ${ }^{[11]}$.

Solid nuclear detectors, by their diverse nature can be used to detect almost all types of heavy charged radiation. For this reason, these detectors can be used successfully among others in mapping the distribution of nuclear contamination ${ }^{[12]}$.

Their simplicity, ruggedness, existence of thresholds for registration and different energy loss for different particles, make solid plastic nuclear detectors particularly suitable when it comes to the search for different particles, this can be done successfully for integrated counting.

The exposure of polymers to nuclear radiation my causes degradation, which can be used as a sign for dose received by the detector. Polyvinyl chloride one of these materials, it was a subject of many investigations ${ }^{[13]}$.

Irradiated PVC as insulation has many benefits ${ }^{[14]}$. It going to with stand much higher temperatures than regular PVC insulation, the one which exposed to radiation, my cause the insulation to become more far superior to ordinary one in temperature, abrasion and cut-through resistance.

This effects was due to cross-linking, this can be accomplished chemically or by irradiation.
Irradiation is the preferred method of cross-linking PVC as is does not use high temperatures or pressure and can be done on small conductor sizes. During the process of irradiating PVC, the material is exposed to a controlled beam of electron radiation. All of these signs can be used for nuclear radiation detection.

It is very important to check the effect of different nuclear radiation on polyvinyl chloride and it's structure by using spectrometry, a commercially available polymer have been investigated and found that it could be used as an solid state nuclear plastic detectors. The polymeric material use in this work was checked by using chemical analysis and IR spectroscopy, and it was found to be polyvinyl chloride with chemical formula [ $\left.-\mathrm{CH}_{2} \mathrm{CHCl}-\right]_{\mathbf{n}}$.

\section{2- Experimental Procedure}

Samples of Polyvinyl Chloride and CN-85 have been cut in form of $1 \times 3 \mathrm{~cm}$ and the irradiated spot have been marked, this spot should be used to pass UV through it, to see the effect of radiation for different doses on optical density passing the spot. Alpha source used in this work was Am241. This source was supplied by the Radiochemical LTd., Amersham, England. Alpha Particles from Am241 source, normally incident on samples. The material use in this work were polyvinyl chloride and Kodak CN-85 cellulose nitrate film, manufactured by Kodak Pathe - France.

Samples were irradiated inside a Canberra cylindrical chamber, Spectro SC from Labomed, Inc. USA, has been used as spectrophotometer to measure absorption spectrum for the samples used in this work.

\section{3- Results and discussion}

$\mathrm{CN}-85$ films were exposed normally to alpha particles and for different doses, the UV spectra for these detector was measured, as shown in Fig.(1) . 
The UV-visible spectroscopy was used to investigate the effect of different doses on the absorption spectroscopy. These samples were exposed to a range of doses between $0 \mathrm{mGy}$ to 19 mGy, The irradiated samples responded to the doses exposed by increasing in the absorbance with dose, and the maximum absorbance was at wavelength $320 \mathrm{~nm}$. For a single dose there is decrease in absorbance with increasing in the wavelength.

At maximum absorbance best fit have been done as shown in Fig.(2) for different doses, this figure shows slightly curved, increasing with it's slope, as doses increased.

Difference in absorbance between a zero dose and different given doses, have been shown in Fig. $(3 a-3 g)$, a peak shown in absorbance differences curve at $320-350 \mathrm{~nm}$, and start to shape up with shifting towered higher wavelength . Amount of absorbance for difference absorbance curve start to increased from low level to higher level with increasing doses, as shown in Fig.(4) . This curve starts to cross over at $16.8 \mathrm{mGy}$.

Absorbance differences curve at different doses is given at Fig.(5), this curve shows increasing response with the dose, this response was slightly curved.

In case of polyvinyl chloride, samples were exposed to alpha charged particles. Absorbance was measured for these samples after exposed them for different doses, between $0 \mathrm{mGy}$ to 19 $\mathrm{mGy}$, this measurement was done in a wavelength range between $320-800 \mathrm{~nm}$, as shown in Fig.(6) . At maximum absorbance, absorbance at different doses have been compared, this gave a function close to linear, as shown in Fig.(7) . Differences in absorbance between zero and different doses have been worked out, to get differences absorbance curve as shown in Fig. (8a-8g). Absorbance differences for different doses used in this work were shown in Fig.(9) which show clear decreasing in absorbance with wavelength comparing to $\mathrm{CN}$ 85 samples.

The response curve get it from samples was mostly linear, for different doses between $6 \mathrm{mGy}$ to 19 mGy.
Polyvinyl chloride shows more response to nuclear radiation than cellulose nitrate $\mathrm{CN}-85$, that was for different doses at range between $6 \mathrm{mGy}$ to $19 \mathrm{mGy}$.

This response was more linearity in polyvinyl chloride, than in CN-85. This will encourage researcher to work with Polyvinyl chloride rather than $\mathrm{CN}-85$ in this dose range, under present condition, this work was done for the first time on this commercial Polyvinyl chloride.

\section{4- Conclusion}

UV-visible absorption spectra of the deference between irradiated and not irradiated, shown a spectrum with a maximum absorption is around $320 \mathrm{~nm}$.

Response curve, absorbance difference curve which represent the pure effect of the dose as shown in Fig.(10), it was mostly linear in polyvinyl chloride in the dose range used in this work, rather than in $\mathrm{CN}-85$, also more higher in value than respective curve in $\mathrm{CN}-85$, by about $114 \%$, it fixed at all doses range used in this work. The linearity of response, with higher value in response curves suggest that polyvinyl chloride can be used as dosimeters. This work has been originated by our team. 


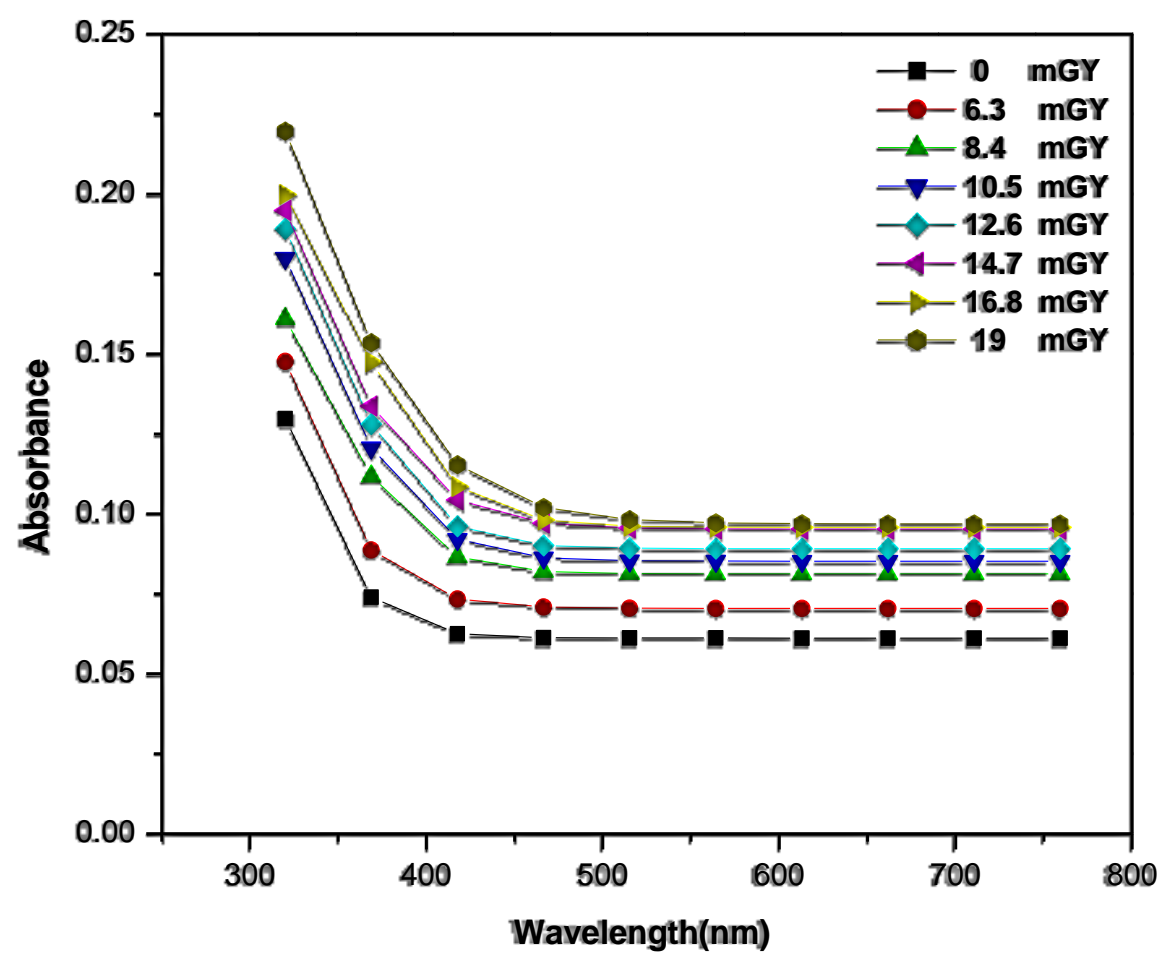

Fig.(1): Absorbance as a function of Wavelength for $\mathbf{C N - 8 5}$

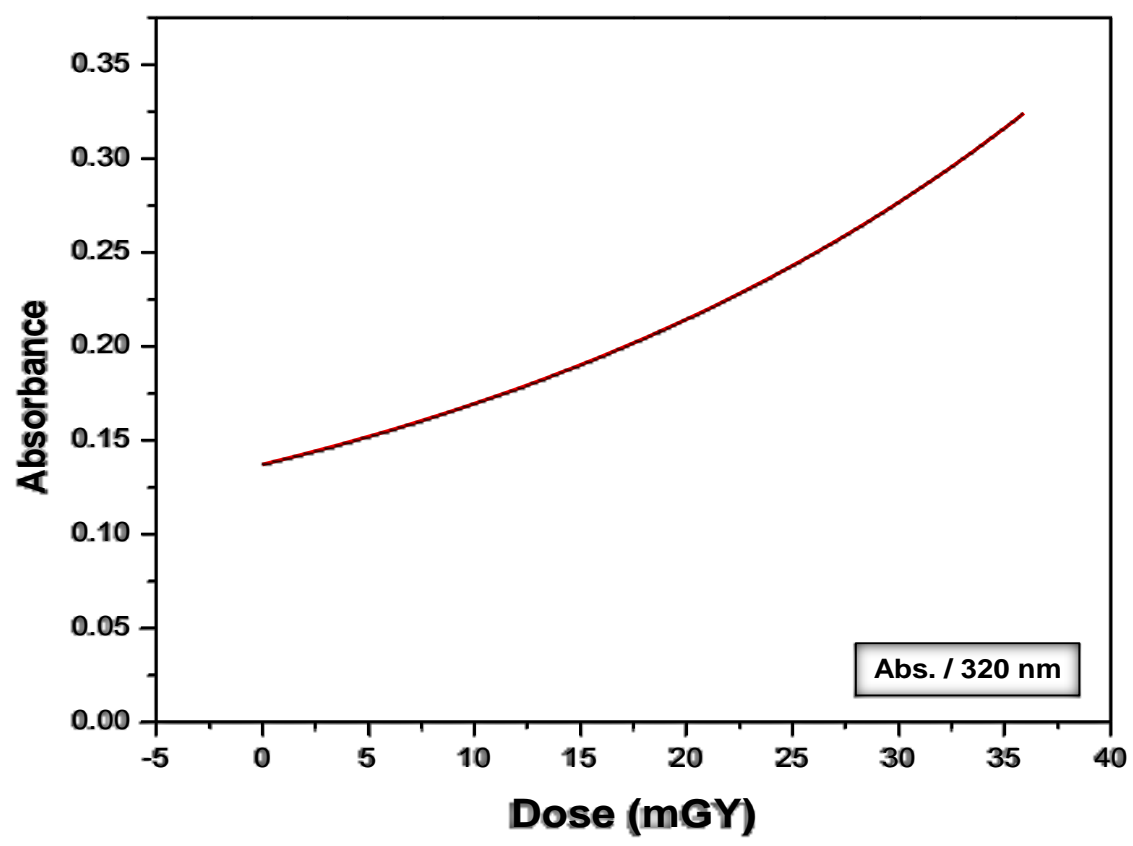

Fig.(2): Absorbance best fit as a function of Doses for $\mathbf{C N - 8 5}$ 


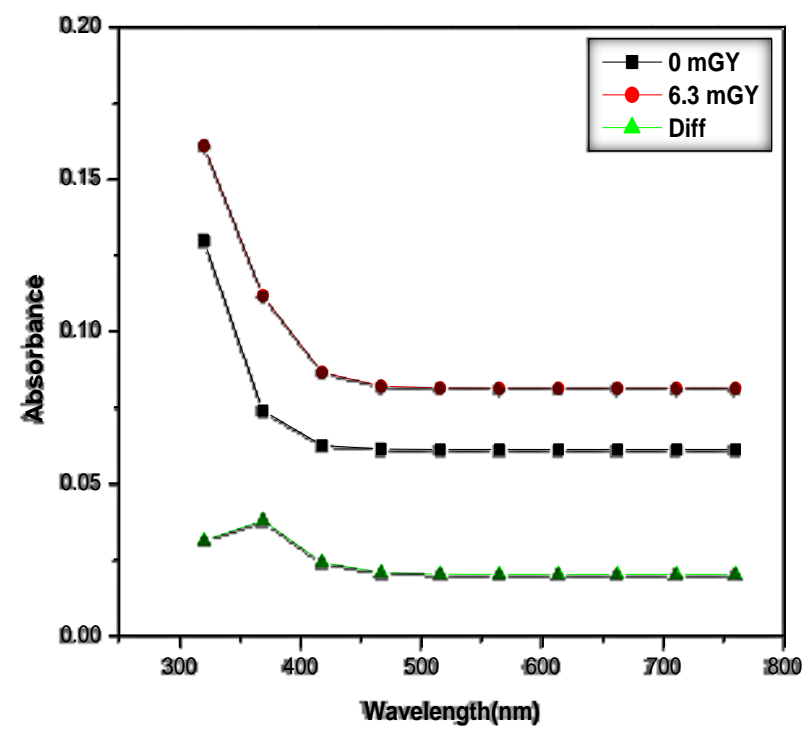

(a)

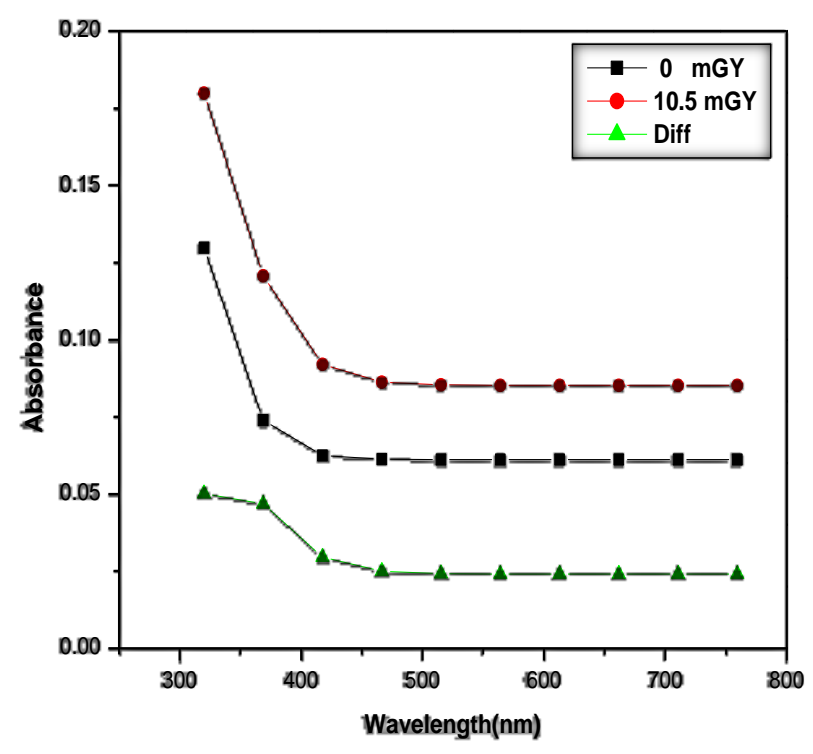

(c)

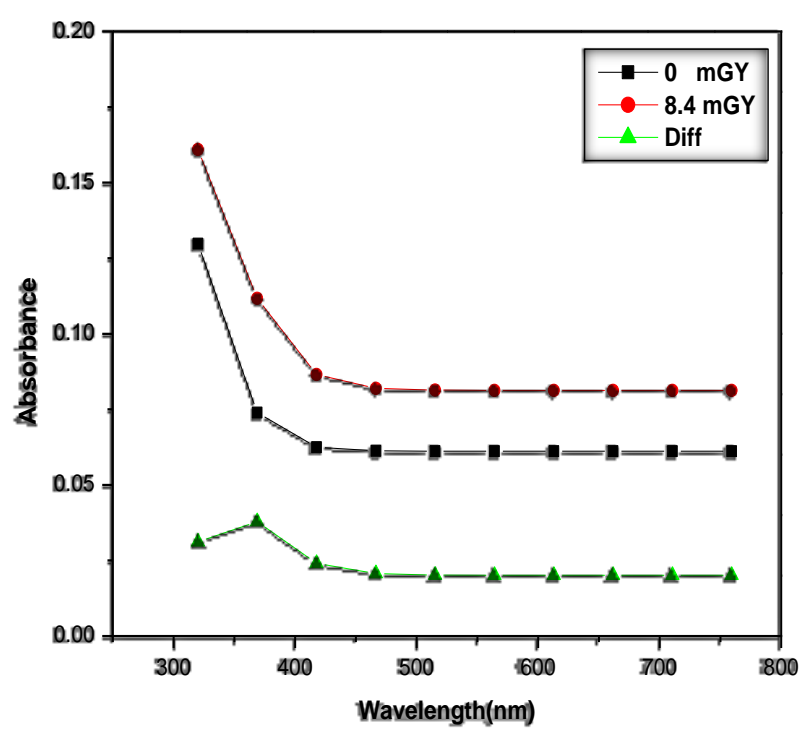

(b)

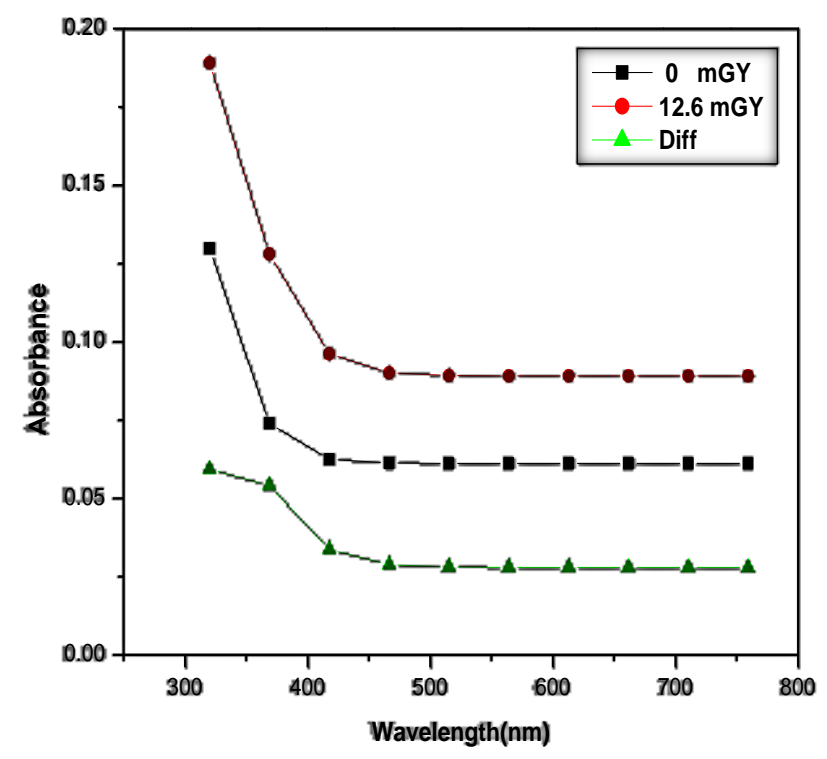

(d) 


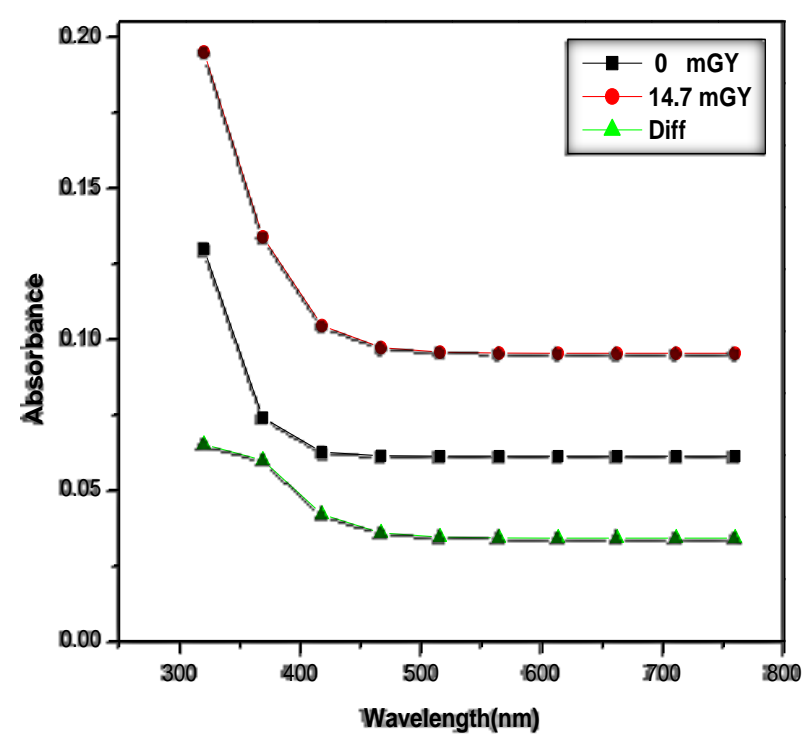

(e)

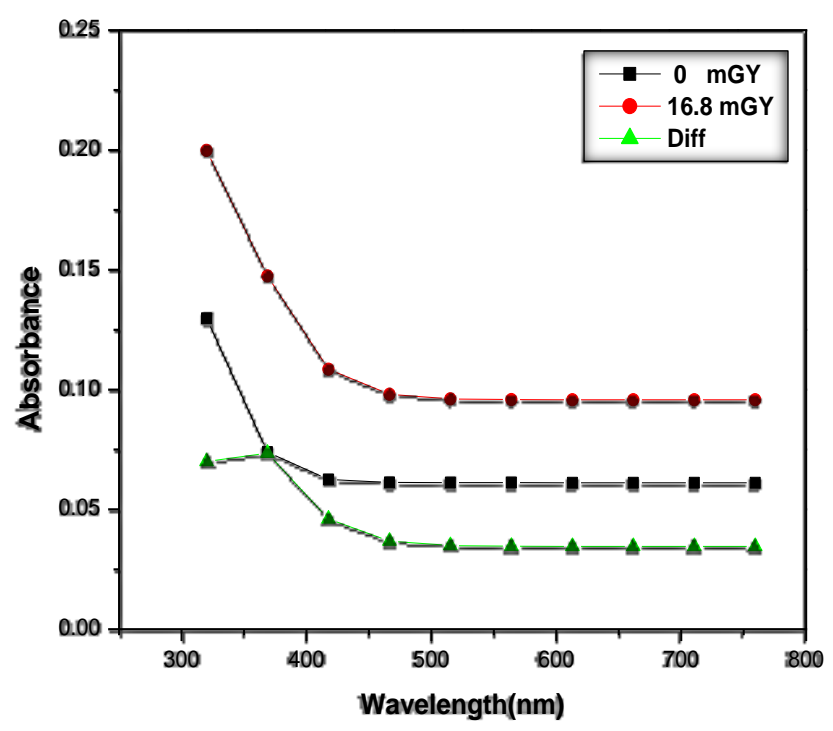

(f)

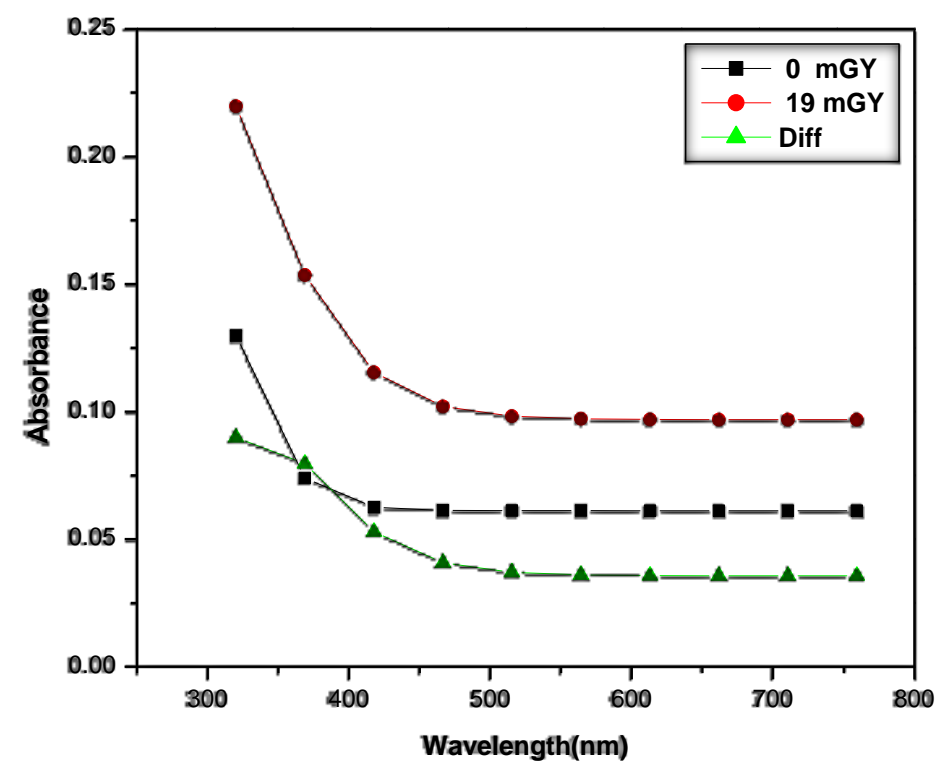

(g)

Fig.(3a-3g): Absorbance difference as a function of Wavelength for $\mathbf{C N - 8 5}$ by using $\mathbf{A m}^{241}$. 


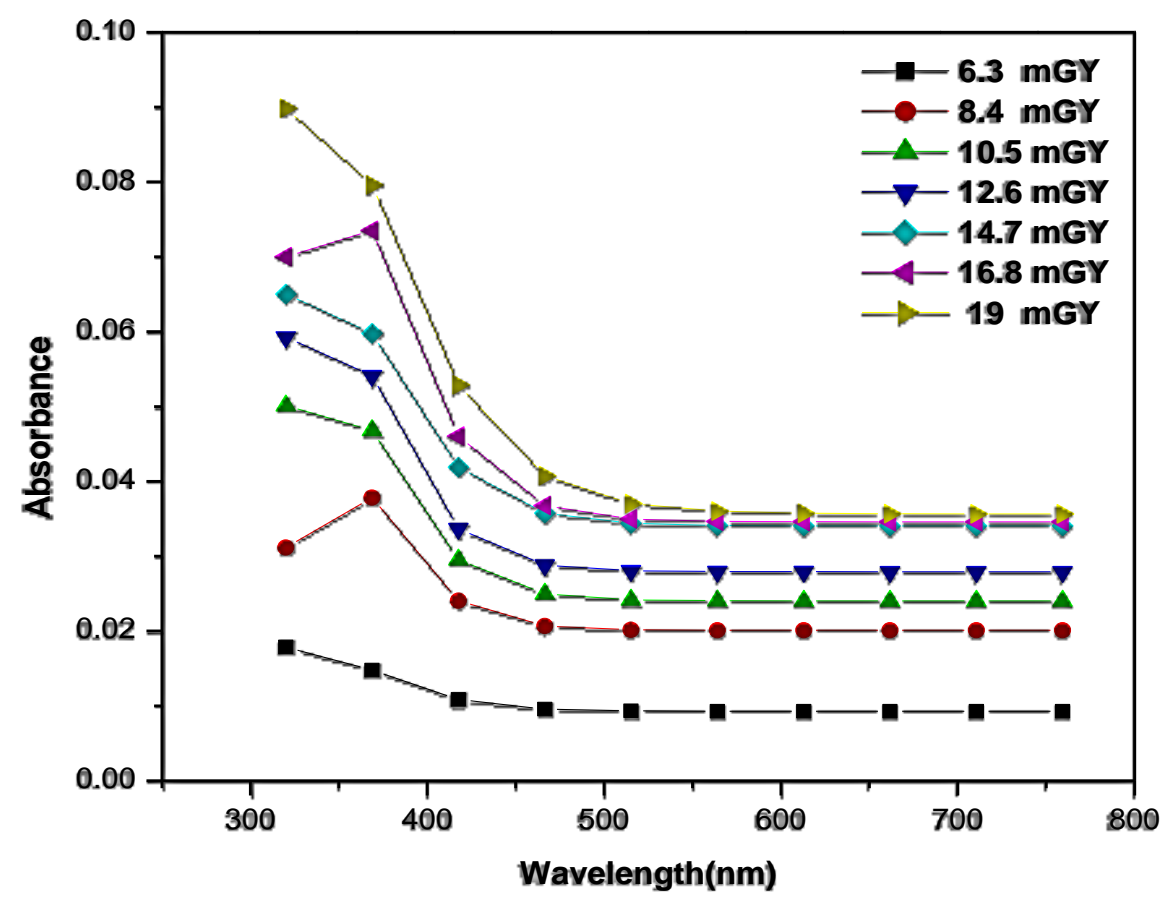

Fig.(4): Absorbance difference as a function of Wavelength for $\mathbf{C N}-85$

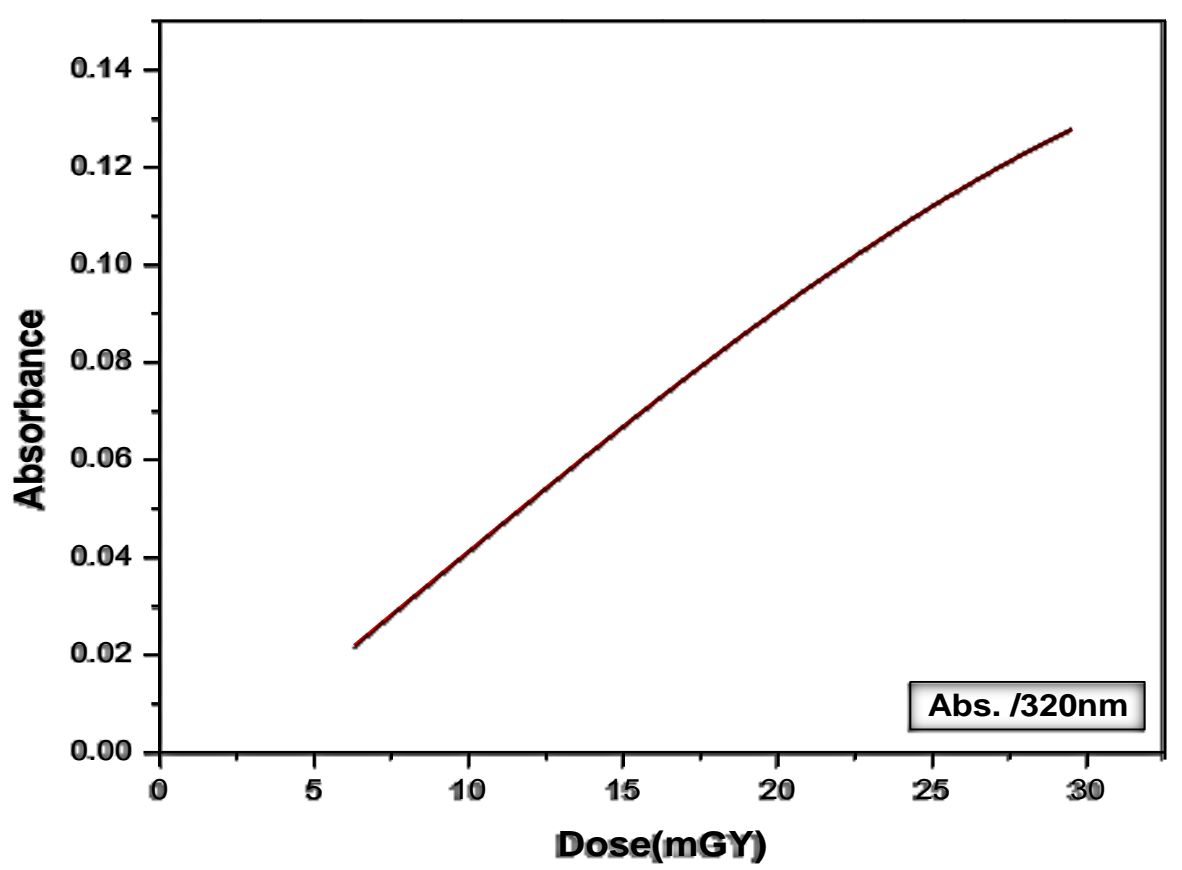

Fig.(5): Absorbance best fit as a function of Doses for $\mathbf{C N - 8 5}$ 


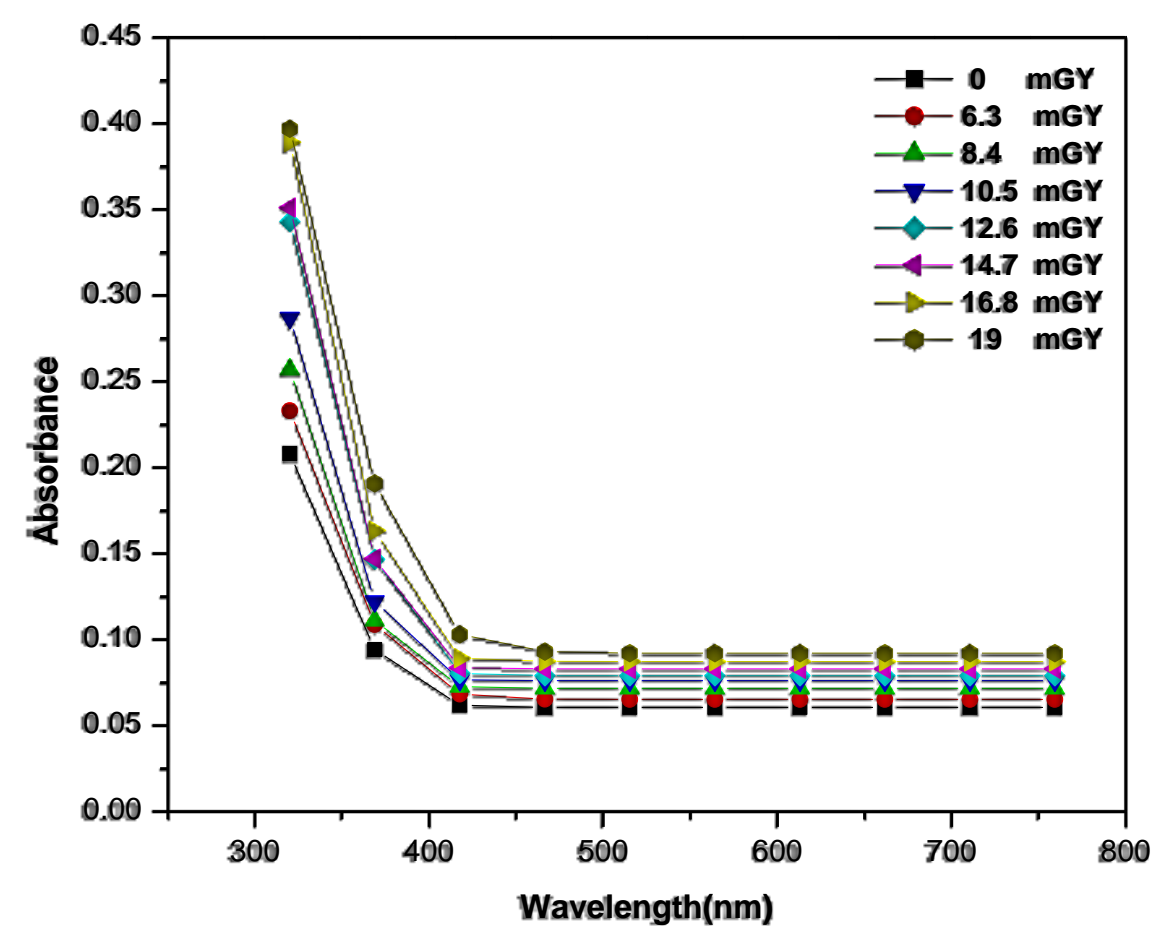

Fig.(6): Absorbance as a function of Wavelength for PVC .

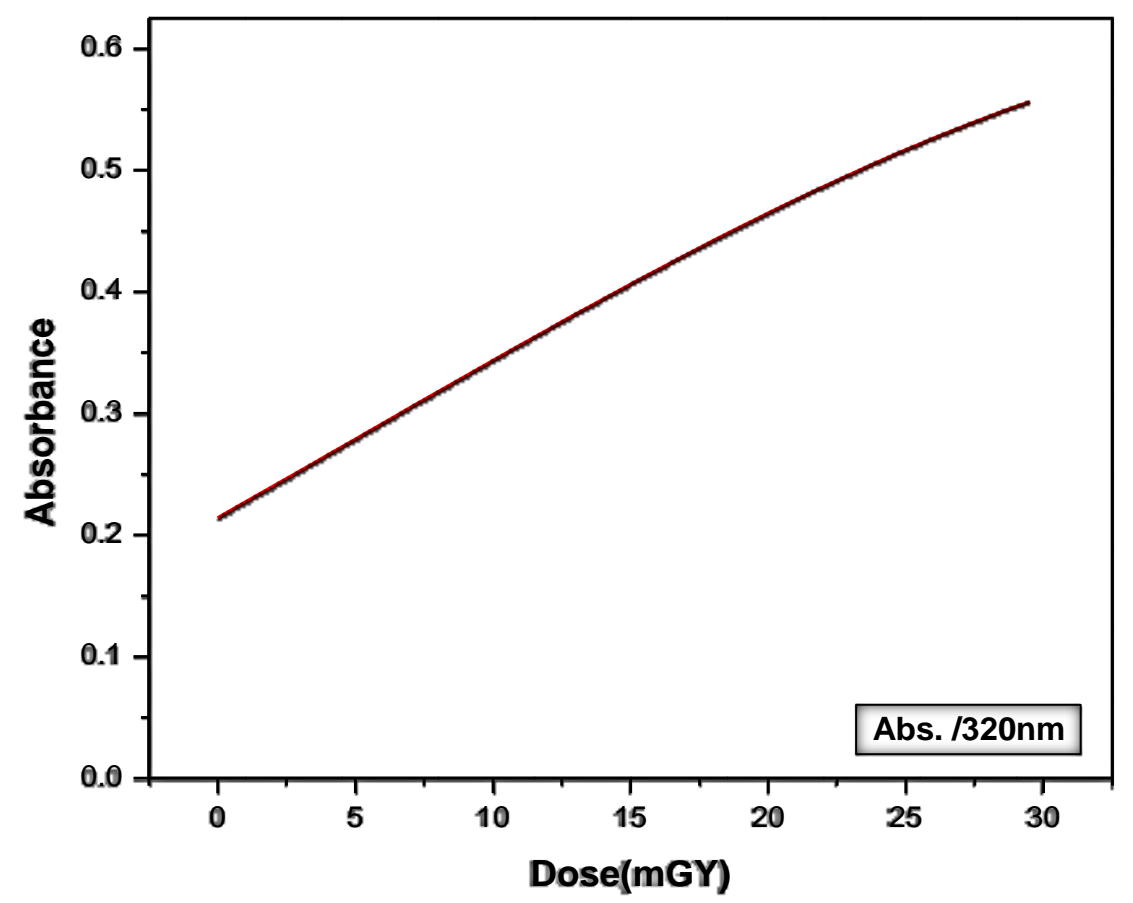

Fig.(7): Absorbance best fit as a function of Doses for PVC . 


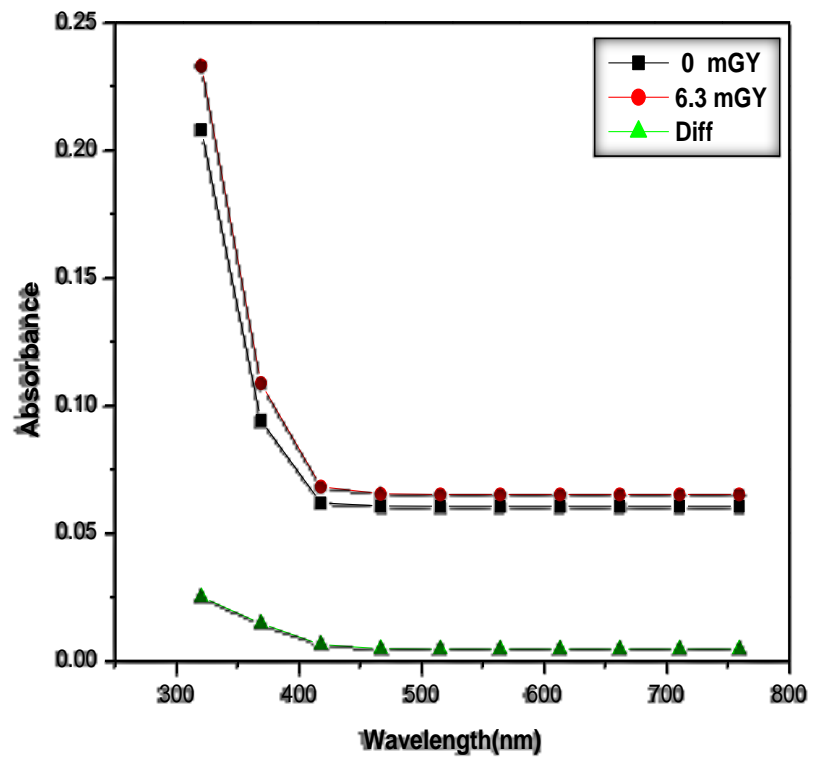

(a)

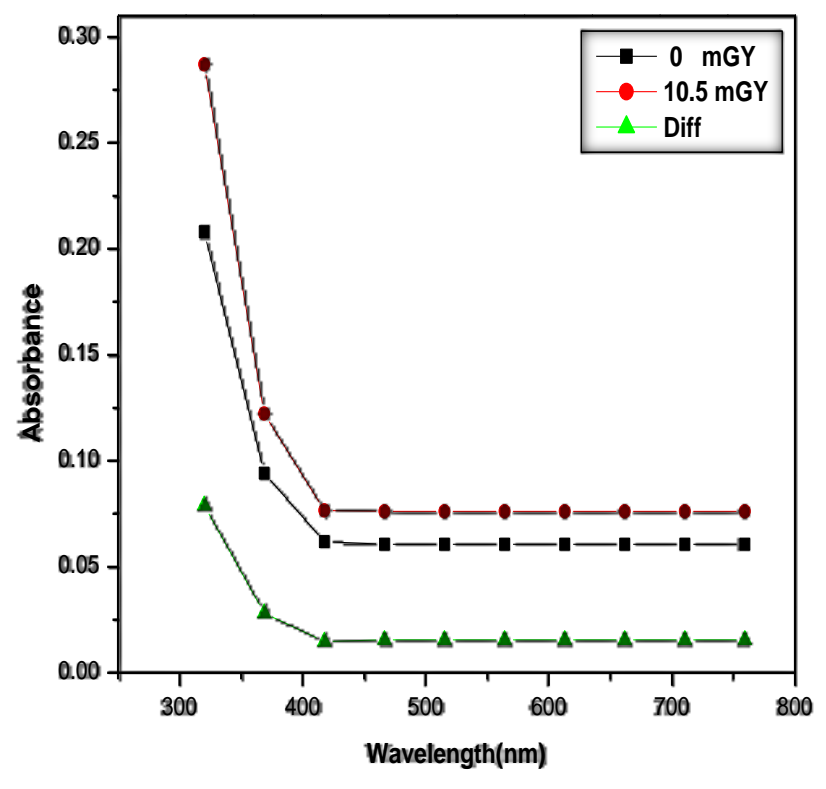

(c)

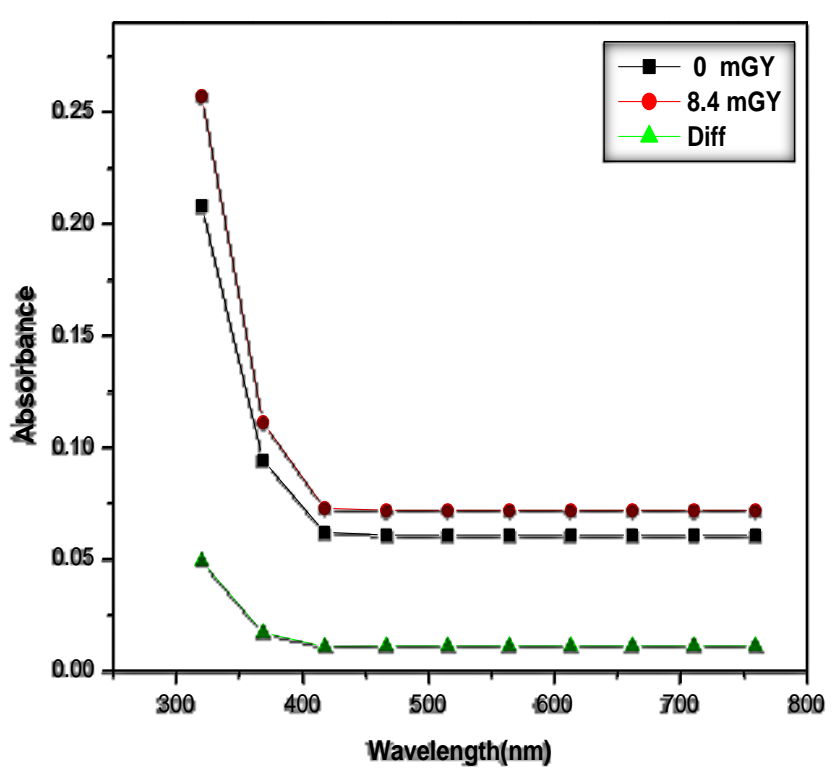

(b)

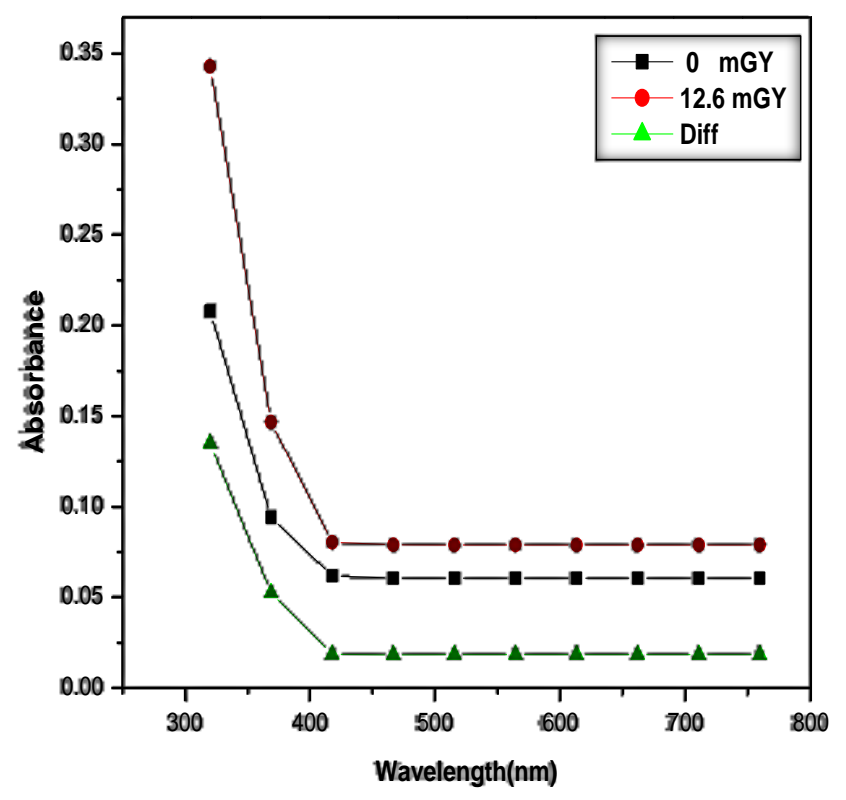

(d) 


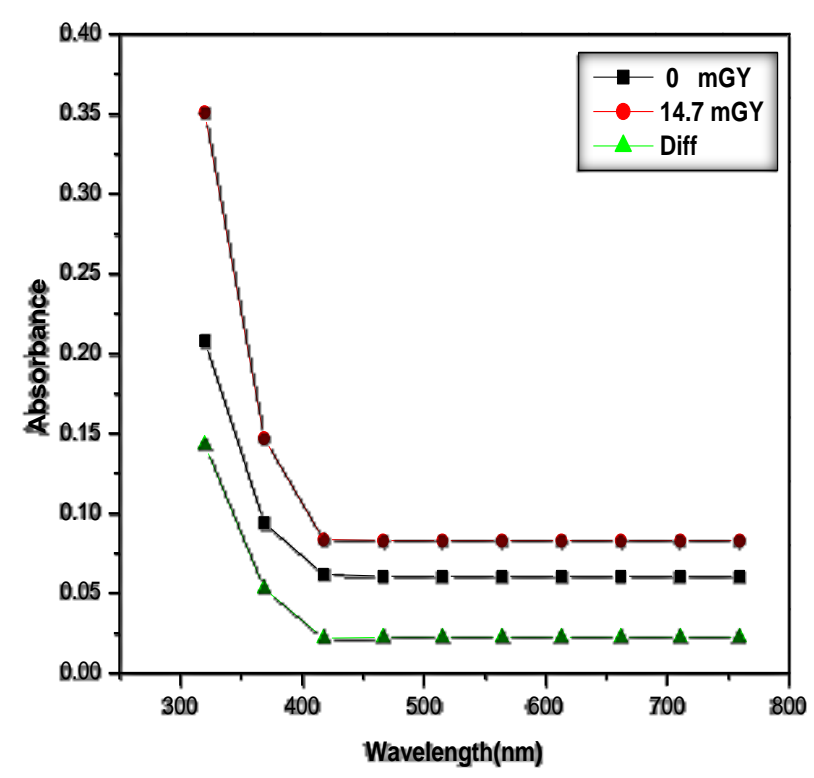

(e)

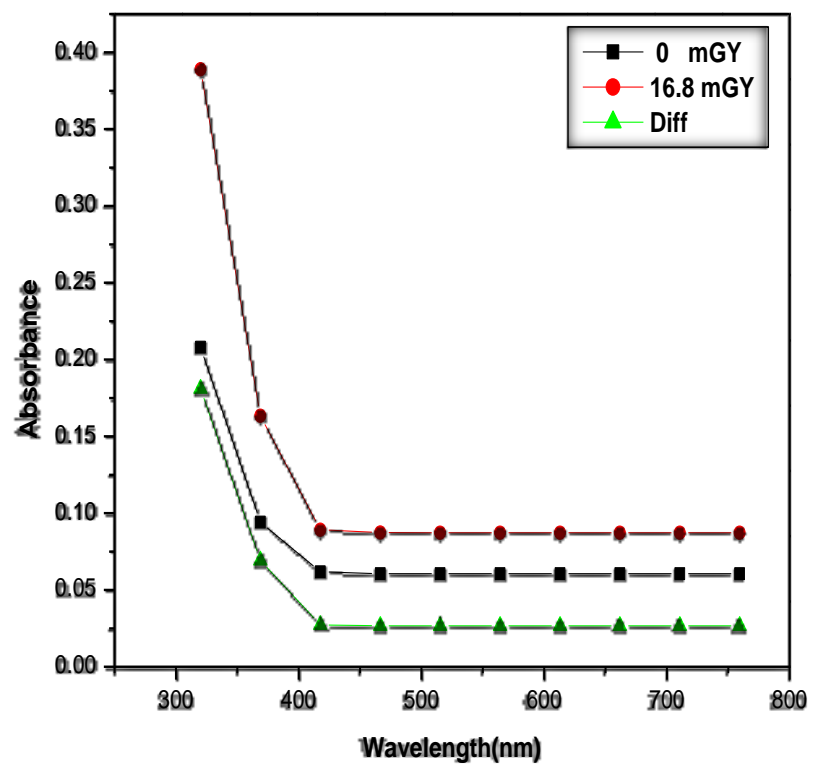

(f)

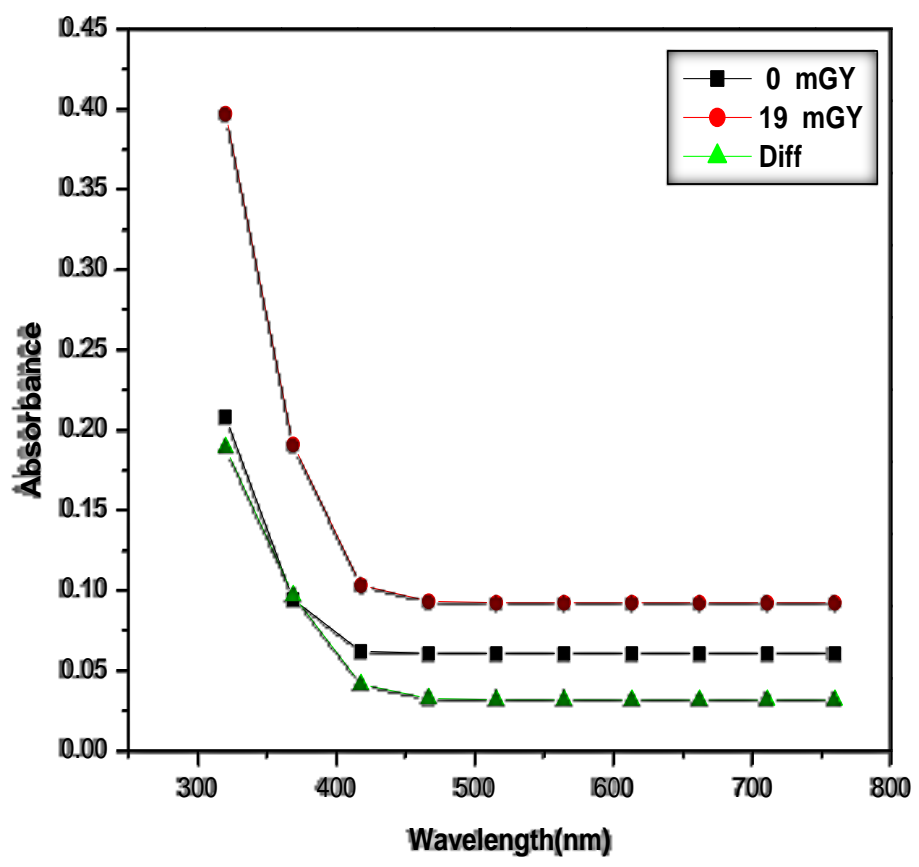

(g)

Fig.(8a-8g): Absorbance difference as a function of Wavelength for PVC by using $\mathbf{A m}^{241}$. 


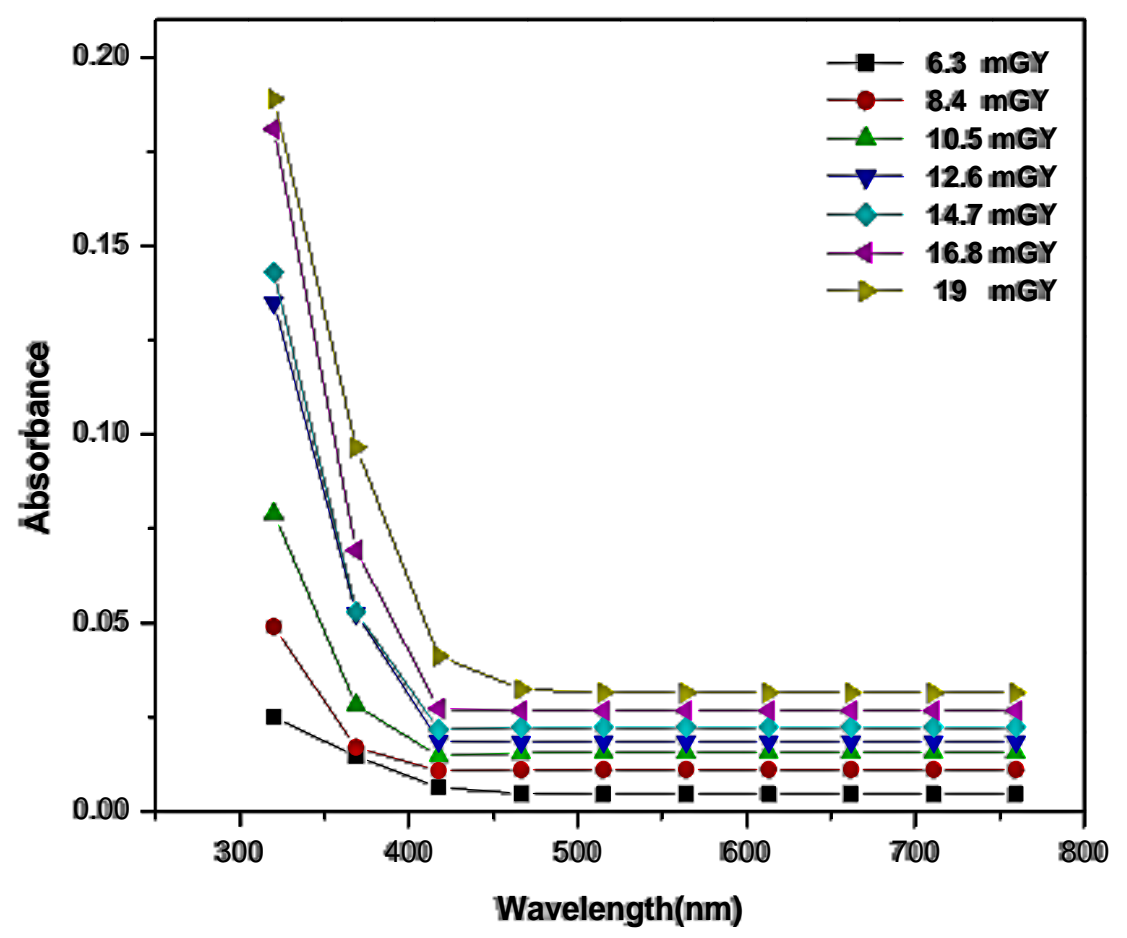

Fig.(9): Absorbance difference as a function of Wavelength for PVC .

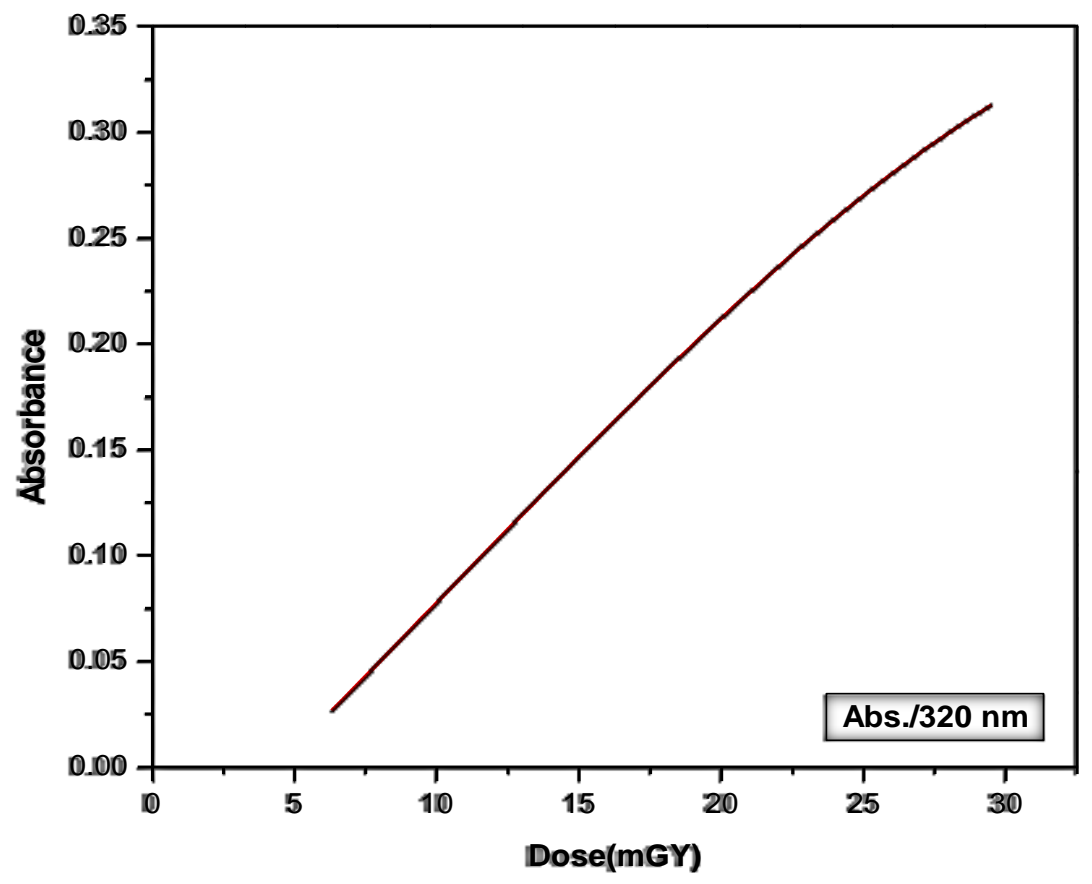

Fig.(10): Absorbance best fit as a function of Doses for PVC . 


\section{References}

[1] H.A.Hussain, T. A. Selman, ((2012)) "AlphaParticle Profiles", Journal of Basrah Researches ((Sciences)) Volume38. Number 2.A.

[2] R.L. Fleischer, P.B. Price, R.M. Walker, (1965) Nucl. Sci. Engin., 22, 153-156 .

[3] R.L. Fleischer, P.B. Price, R.M. Walker, (1975) Nuclear Tracks in Solids Principles and Applications, University of California Press, Berkeley .

[4] C.P. Dewolf, C.J. Zeissler, A.N. Halliday, K. Mezger, E.J. Essene, (1986) Geochim Cosmochim , Acta, 60, 121-134 .

[5] S. Singh, B. Singh, A.S. Sandhu, G. Singh, Rad. Meas., (1999) 31, 687-690 .

[6] G.R. Choppin, J.O. Liljenzin, J. Rydberg, Radiochemistry and Nuclear Chemistry, (2001) Butterworth-Heinemann, Oxford.

[7] S.A. Durrani, R.K., Bull. Solid State Nuclear Track Detection: Principles,

Methods and Applications, (1987) Pergamon Press,.

[8] M.A. Geyh, H. Schleicher, Absolute Age Determination, (1990) Springer, Berlin.

[9] A. Dickin, Radiogenic Isotope Geochemistry, (1995) Cambridge University Press,.

[10] P. van den Haute, F. De Corte (Eds.) Advances in Fission-Track Geochronology, (1998) Kluwer Academic, Dordrecht,.

[11] M. Rogestedt and T. Hjertberg, Macromolecules, (1993) 26, 60 .

[12] N. Benseman, T. Van Hoang, A. Guyot, Polym. Degrd. Stab., (1990) 28, 173 .
[13] M. Rogestedt and T. Hjertberg, Polym. Degrd Stab., (1994 ) 45, 19 .

[14] Allied Wire \& Cable, Irradiated PVC, September (2006) Newsletter, . 